\title{
Metodologia internacional de avaliação por microscopia de rações para ruminantes e coprodutos de origem animal
}

\author{
Janaína Farias Rossetto ${ }^{1}$, Heloísa Helena Kreibich $^{1}$ \& Vildes Maria Scussel ${ }^{1 *}$ \\ ${ }^{1}$ Laboratório de Micotoxicologia e Contaminantes Alimentares, Departamento de Ciência e Tecnologia, Centro \\ de Ciências Agrárias da Universidade Federal de Santa Catarina - UFSC, Florianópolis, SC. \\ *Autor para correspondencia,E-mail: vildescussel_2000@yahoo.co.uk
}

\begin{abstract}
RESUMO. A Encefalopatia Espongiforme Bovina (EEB) é causada por uma proteína chamada príon responsável pela degeneração do sistema nervoso em seres humanos e animais. A forma clássica da doença ocorre com a ingestão de proteína animal contaminado com o príon infeccioso. O Ministério da Agricultura, Pecuária e Abastecimento é responsável pela promoção de controle e prevenção desta doença no país devido à transmissão da doença de ruminantes para humanos. O Brasil é um grande produtor de alimentos para animais, assim, é importante o controle efetivo de ingredientes para alimentação animal. Subprodutos de origem animal (farinha de cascos e chifres, carne e ossos, penas, farinha de peixe, vísceras de aves, ossos não calcinados, ossos calcinados e produtos lácteos) são importantes para a suplementação protéica e mineral na alimentação de ruminantes. No entanto, apenas os ossos cozidos no vapor e produtos lácteos são permitidos para ruminantes. Foi relatada a avaliação macro e microscópico de rações, suplementos e subprodutos de origem animal (OA), o que permitiu a caracterização dos diferentes tecidos. As análises macroscopicas foram realizadas durante a preparação da amostra e, em seguida microscopicamente (estereoscopia e por fluorescência) para identificar os ingredientes, se podiam (ou seja, incluídos na lista) nas normas estabelecidas. O limite de detecção do método (LD) nas amostras fortificadas (farinha de sangue, osso não calcinado em pó, farinha de penas e cascos e chifres) chegou até $0,05 \%$, o que foi confirmado por testes químicos específicos. LD obtidos forneceram confiabilidade aos resultados e permitiram o desenvolvimento da acuidade visual analista. O método microscópico para a detecção de subprodutos animais foi eficaz e considerada uma ferramenta útil, de fácil execução e de baixo custo para mitigar o risco de EEB.
\end{abstract}

Palavras chave: EEB, limite de detecção, microcospia, rações, ruminante, subprodutos animais.

\section{Evaluation of international methodology microscopy-based for ruminants feed animal origem ingredients identification}

ABSTRACT. The Bovine Spongiform Encephalopathy (BSE) is caused by an infectious
protein called prion responsible for the nervous system degenerationof humans and
animals. The classic form of the disease occurs with the intake of animal protein
contaminated with the infectious prion. The Ministry of Agriculture, Livestock and
Supply is responsible for promoting control and prevention of this disease in the country
due to the posiblerisk of disease transmission to ruminants. Brazil is a major feed
producer thus, it is important the effective control of feed ingredients. Animal by-
products (flour hooves and horns, flesh and bones, feathers, fish, poultry viscera, bones
not calcined, calcined bones and dairy products) are important for protein and mineral
supplementation of ruminants diet in (however, only the steamed bones and dairy
products are allowed for ruminants). We report the macro and microscopic evaluation of
feed, supplements and by-products of animal origin (OA) carried out in the
microscopylaboratory, Southern Brazil, which enabled the characterization of difference
AO tissues. Analysis were performed macroscopically during the sample preparation and
then microscopically (by stereoscopy and fluorescence) to identifythe ingredients,
whether they were allowed (i.e., included in the list) in theestablished standards. The 
metods detection limit (LD) in the fortificated samples (blood meal, bone non-calcined powder, feather meal and hooves and horns flour) reached up to $0.05 \%$ which was confirmed by specific chemical tests. LDobtained provided reliability to the results and enabled the development of analyst visual acuity. The microscopic method for the detection of animal by-products was effective andconsidered and useful tool, easy to perform and inexpensive to mitigate the risk of BSE.

Keywords: BSE, detection limits, microcospy, diets, ruminants, coproducts.

\section{Introdução}

O Brasil possui o segundo maior rebanho bovino do mundo com 200 milhões de cabeças, contribuindo na produção de leite e sendo o maior exportador mundial de carne desde 2004 (Brasil, 2015). Isto se deve à ampliação das pastagens, melhoramento de raças, correção e fertilização do solo, medidas sanitárias profiláticas, além do confinamento dos animais antecipando o abate (Bittar, 2006). O alto nível de qualidade dos ingredientes e rações para uso animal torna os gastos com alimentação em torno de 60 a $70 \%$ dos custos totais com a criação animal (Gabbi, 2011).

A utilização de proteína animal na composição de rações the confere alto valor nutritivo, visto que é um material rico em aminoácidos, lipídios, minerais e vitamina $\mathrm{B}_{12}$ (Fireman, 2010). Todavia, a utilização de alguns tipos de subprodutos de origem animal (OA) na alimentação de ruminantes (farinha de cascos $e$ chifres - FCC, farinhas de carne e ossos- FCO, farinhas de penas- FP), farinhas de peixe - FPx, farinhas de sangue- FS, farinhas de víscera de aves (FVA), e ossos não calcinados (ONC), vem sendo proibida no Brasil (exceto ossos calcinados - OC e derivados do leite - DL) desde 1996 (Brasil, 2008), devido à ocorrência de Encefalopatia Espongiforme Bovina (EEB), a Mad Cow Disease. Essa doença ataca o gado causando a degeneração progressiva do tecido nervoso (Momcilovic \& Rasooly, 2000; Raamsdonk et al., 2011). O Brasil registrou somente um caso de EEB atípica no Mato Grosso em 2014 causada pela idade avançada do animal, não possuindo nenhuma ligação com a ingestão de alimentos contaminados (OIE, 2015).

Portanto, é necessária a aplicação de métodos para viabilizar a identificação de ingredientes de rações e subprodutos de $\mathrm{AO}$ advindos do processamento de carcaças e partes delas (aves, mamíferos, e peixes). Aavaliação é importante devido à grande variação de qualidade das farinhas existentes no mercado e dificuldade na detecção de fraudes (Khajarern \& Khajarern, 1999). Os métodos mais comuns são o de Wende, de Van Soest, imunoensaios e a reação em cadeia da polimerase, contudo a análise microscópica é o método oficial para análise de subprodutos em rações para ruminates (Butolo, 2002; Sanches et al., 2006). O método é rápido e de baixo custo, faz uso de microscópios (estereoscópio e óptico de fluorescência) para caracterizar seus ingredientes e é considerada adequada às normas estabelecidas (AAFM, 1992). Depende quase que exclusivamente da habilidade visual/sensorial do analista em identificar os constituintes (pela sua forma, cor, tamanho, textura, dureza, brilho, odor e conhecimento da estrutura celular) de tecidos animais e vegetais. Pode ser complementada com testes químicos específicos conforme a composição dos tecidos (UE, 2009; Brasil, 2003).

Este trabalho caracterizou microscopicamente os principais subprodutos de OA utilizados na alimentação de ruminantes e estabeleceu os limites de detecção (LDs) do método aplicado para cada subproduto, utilizando provas químicas de confirmação.

\section{Material e Métodos}

Amostras: foram utilizadas rações para ruminantes, suplementos para rações e padrões de subprodutos de AO.

(a) Rações para ruminantes: (a.1) granuladas (total: 14 amostras - farelos de arroz, milho, soja, sorgo e trigo) e (a.2) peletizada (total: 01 amostra - farelos de milho e soja triturados, prensados e estrusados, em formato tubular: 10/3/1, 5mm);

(b) suplementos para rações: pó (total: 05 amostras - minerais: carbonatos, fosfatos e cloretos). Todas as rações para ruminantes e os suplementos (20 amostras) foram obtidos nos estados da Região Sul (de agosto a dezembro de 2014), acondicionados em embalagens plásticas;

(c) Padrões de subprodutos de (OA): partes não comestível dos seguintes animais: aves (penas e vísceras); peixes (cabeça, escamas, 
ossos e vísceras) e suínos/bovinos (cascos, chifres, ossos, sangue e vísceras), totalizando 12 amostras. Se apresentavam sob a forma de farinha de cascos e chifres (FCC), farinhas de carne e ossos (FCO), farinhas de penas (FP), farinhas de peixe (FPx), farinhas de sangue (FS), farinhas de víscera de aves (FVA), ossos calcinados (OC) e ossos não calcinados (ONC). Esses subprodutos foram utilizados como Material de Referência (MR), contendo códigos MR/ALA/SLAV (para checagem de adulteração na composição de ingredientes para rações de ruminantes).

Reagentes: ácido sulfúrico (Química Moderna), ácido clorídrico (Biotec), glicerina (Vetec), ácido acético glacial (Lafan), acetato de chumbo (Vetec) e hidróxido de sódio (Panreac), todos p.a. Solventes: clorofórmio (Vetec) e éter etílico (Panreac), todos p.a; além de água (destilada e deionizada). Soluções: ácido clorídrico (6M), hidróxido de sódio (10\%), acetato de chumbo (5\%), ácido acético (50\%) (Khajarern\& Khajarern, 1999; Morita \& Assumpção, 2007; UE, 2009). Todas armazenadas em frascos âmbar/conta-gotas. Sistema de solventes: clorofórmio: éter etílico (70:30).

\section{Equipamentos}

Microscópios: estereoscópio, modelo SZX16 (Olympus), aumento máximo de 70x, com câmera (Canon), modelo Power (Shot S5 IS) para fotomicrografia digital com resolução de 8.0 megapixels. (b) óptico de fluorescência, modelo Axiostar Plus (Zeiss), aumento máximo de 1000 vezes.
Balanças: analítica (Mettler Toledo), resolução mínina de $10 \mathrm{mg}$ e (b) semi analítica (Edutec), com resolução mínima de $0,1 \mathrm{~g}$.

Outros: capela de exaustão (Lucadema); conjunto de tamises (aberturas de 1,40; 1,00 e $0,5 \mathrm{~mm}$ ) (Bronzinox); estufa de esterilização.

Secagem (DeLeo): sonda exploradora e software para análise de imagens (Zoom Browser EX), compatível com sistema operacional Windows 97.

Coleta das amostras: as rações e suplementos (cerca de $1 \mathrm{a} 2 \mathrm{~kg}$ ) foram adquiridas por fiscais do MAPA (agosto a dezembro de 2014) das indústrias do Paraná, Rio Grande do Sul e Santa Catarina de forma representativa, em sacos plásticos e embaladas em de caixas de papelão $(81 \times 12,50 \mathrm{~cm})$ e registradas conforme códigos estabelecidos pelo Laboratório de Microscopia (LM). Coletadas de forma apropriada para amostragem e homogeneizada. Foram armazenadas em embalagens plásticas e entregues ao LM-SLAV/SC para a realização das análises. Já os subprodutos de OA (MR), estavam em frascos de vidros (Brasil, 2009).

Preparo das amostras: seguiu o método oficial do MAPA descrito na Instrução Normativa (IN) 69/2003, para o preparo de rações, suplementos para rações e subprodutos de OA (Brasil, 2003). O preparo da amostra compreendeu várias etapas (pesagem $\Rightarrow$ flotação $\Rightarrow$ seletividade $\Rightarrow$ secagem $\Rightarrow$ se paração por peneira ou tamização). As Figuras 1 e 2 correspondem ao material utilizado e a sequência analítica das análises, respectivamente.

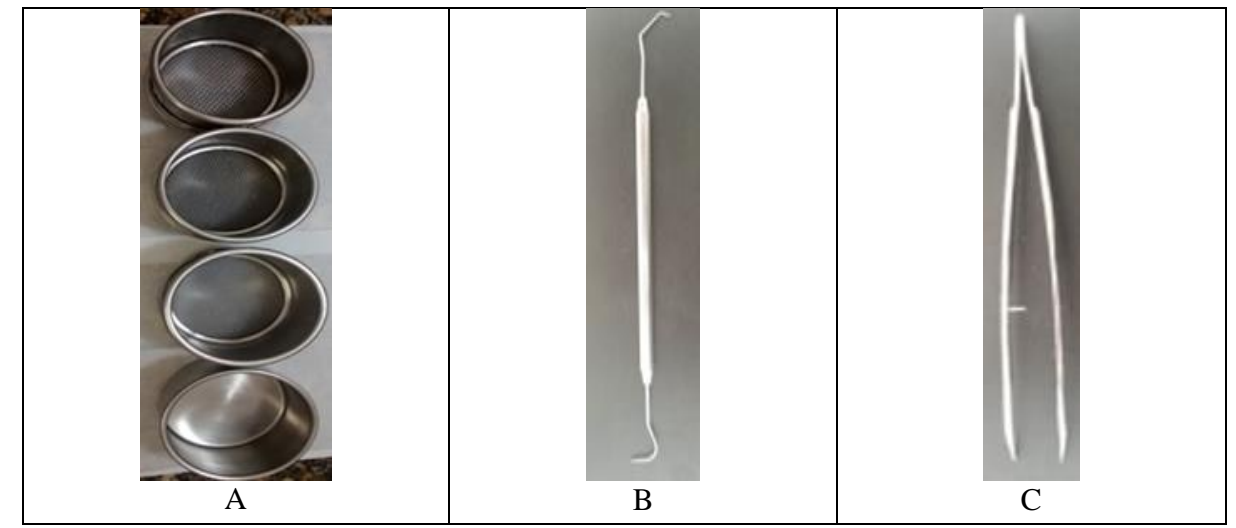

Figura 1 - Material para o preparo e análise de amostras: (A) tamisadorcom malhas de 1,40; 1,0, e 0,50 mm, (B) sonda exploradora e $(\mathrm{C})$ pinça

Análises macro e microscópica: a análise (a) macroscópica (análise preliminar) envolveu avaliação sensorial (visual - cor e formato partícula; olfato - aroma) e as (b) microscópicas 
envolveu duas análises microscópicas (estereoscópico e de fluorescência) e seguiram o método do MAPA descrito na IN 69/2003. (b.1) estereoscópicas - iniciando pela avaliação das frações peneiradas mais grossas a mais finas, examinadas com aumentos de 10 vezes, com auxílio de sonda exploradora. As placas foram examinadas com movimentos leves e por camadas. Foram observadas suas estruturas, cor, textura e dureza (Brasil, 2003). As partículas, cuja análise necessitava de maior cuidado, foram retiradas com auxílio de pinça edepositadas em placas de Petri devidamente identificadas. (b.2) fluorescência - os achados contendo sangue foram levados ao microscópio de fluorescência para visualização de sua estrutura e comprovação das características por fluorescência (Khajarern; Khajarern, 1999). Após esses procedimentos, foram realizadas provas químicas para comprovação da natureza dos achados.

Testes de confirmação do nível de detecção (LD): foram realizados através das etapas de fortificação, microscopia e provas químicas;

(a) fortificação - para avaliação do método para subprodutos de $\mathrm{OA}$ (permitidos e não permitidos pela legislação) (Brasil, 2004), as amostras foram fortificadas com 0,05, 0,1 e 0,2\% de FS, ONC, FP e FCC para posterior análise microscópica e química (Tabela 1). (b): microscopia - as partículas suspeitas foram retiradas, depositadas em placas de Petri devidamente identificadas, re-analizadas ao microscópio e submetidas às provas para confirmação.

(c) provas químicas: foram utilizandos reagentes específicos. Encontrada a menor porcentagem de detecção (LD - limite de detecção) do subproduto de AO estudado, foram preparadas seis replicatas (e um branco Controle) dessa menor porcentagem de fortificação encontrada utilizando o método DOC-CGCRE-008 do Instituto Nacional de Metrologia, Qualidade e Tecnologia (INMETRO) o qual descreve as orientações que devem ser seguidas sobre a validação de métodos analíticos (Brasil, 2010).

Após fortificação, foram seguidos os procedimentos de preparo de amostra, análise microscópica e comprovação por provas químicas, sendo o LD de cada componente estabelecido quano $100 \%$ (seis placas) desse componente fosse encontrado. Caso contrário, o experimento era repetido com a porcentagem imediatamente superior de fortificação. Nota: A pesagem dos cálices foi realizada no dia anterior ao preparo das amostras, porém a randomização, o preparo e a análise foram realizados no mesmo dia e pelo mesmo analista para sua maior veracidade.

Tabela 1 - Níveis de fortificação com subprodutos de origem animal para confirmação do limite de detecção com provas químicas

\begin{tabular}{lccccc}
\hline & Níveisde & \multicolumn{2}{c}{ Matriz $^{\mathrm{a}}, \mathrm{g}$} & \multicolumn{2}{c}{ Fortificação $^{\mathrm{b}}, \mathrm{g}$} \\
\cline { 2 - 5 } Placas & Fortificação, $\%^{\mathrm{f}}$ & $\mathrm{OC}_{1 \mathrm{x}, 2 \mathrm{x}}^{\mathrm{c}}$ & $\mathrm{FPx}_{3 \mathrm{x}} \& \mathrm{FCO}_{4 \mathrm{x}}^{\mathrm{e}}$ & $\mathrm{ONC}_{1 \mathrm{y}}^{\mathrm{f}} \mathrm{FSS}_{2 \mathrm{y}}^{\mathrm{g}}$ & $\mathrm{FP}_{3 \mathrm{y}}^{\mathrm{h}} \& \mathrm{FCC}_{4 \mathrm{y}}^{\mathrm{i}}$ \\
\hline Controle $^{\mathrm{j}}$ & $\mathrm{NA}^{\mathrm{k}}$ & 2,0000 & 15,0000 & $\mathrm{NA}$ & $\mathrm{NA}$ \\
01 & 0,05 & 1,9990 & 14,9925 & 0,0010 & 0,0075 \\
02 & 0,10 & 1,9980 & 14,9850 & 0,0020 & 0,0150 \\
03 & 0,20 & 1,9960 & 14,9700 & 0.0040 & 0,0300 \\
\hline
\end{tabular}

${ }^{\mathrm{a}-\mathrm{b}}$ subprodutos de origem animal (OA), ${ }^{\mathrm{c}}$ ossos calcinados, ${ }^{\mathrm{d}}$ farinha de peixe, ${ }^{\mathrm{e}}$ farinha de carne e ossos, ${ }^{\mathrm{f}}$ ossos não calcinados, ${ }^{g}$ farinha de sangue, ${ }^{h}$ farinha de penas, ${ }^{i}$ farinha de cascos e chifres, ${ }^{j}$ sem fortificação, ${ }^{k}$ nãoaplicável, ${ }_{1 x}$ analito $\mathrm{x}{ }_{1 y}$ fortificação, respectivamente

Provas químicas: para a realização dessas provas para detecção de subprodutos de OA, foram definidos os seguintes OAs a serem pesquisados: FCC, FP, FS e ONC, de acordo com os métodos descritos por Khajarern \& Khajarern (1999) e UE (2009). (a) FCC - fortificada em FCO e utilizou ácido acético 50\% como reagente, (b) FP fortificada em FPx, utilizou soluções dehidóxido de sódio $10 \%$ e de acetato de chumbo 5\%, (c) FS - fortificada em fragmentos de OC queimados e reagente ácido sulfúrico p.a., seguido de avaliação no microscópio de fluorescênciae (e.4) ONC - fortificadoem OC e utilizado o ácido clorídrico como reagente. Foram seguidos, além do método de Khajarern \& Khajarern (1999), os oficiais estabelecidos pela União Europeia (2009) 


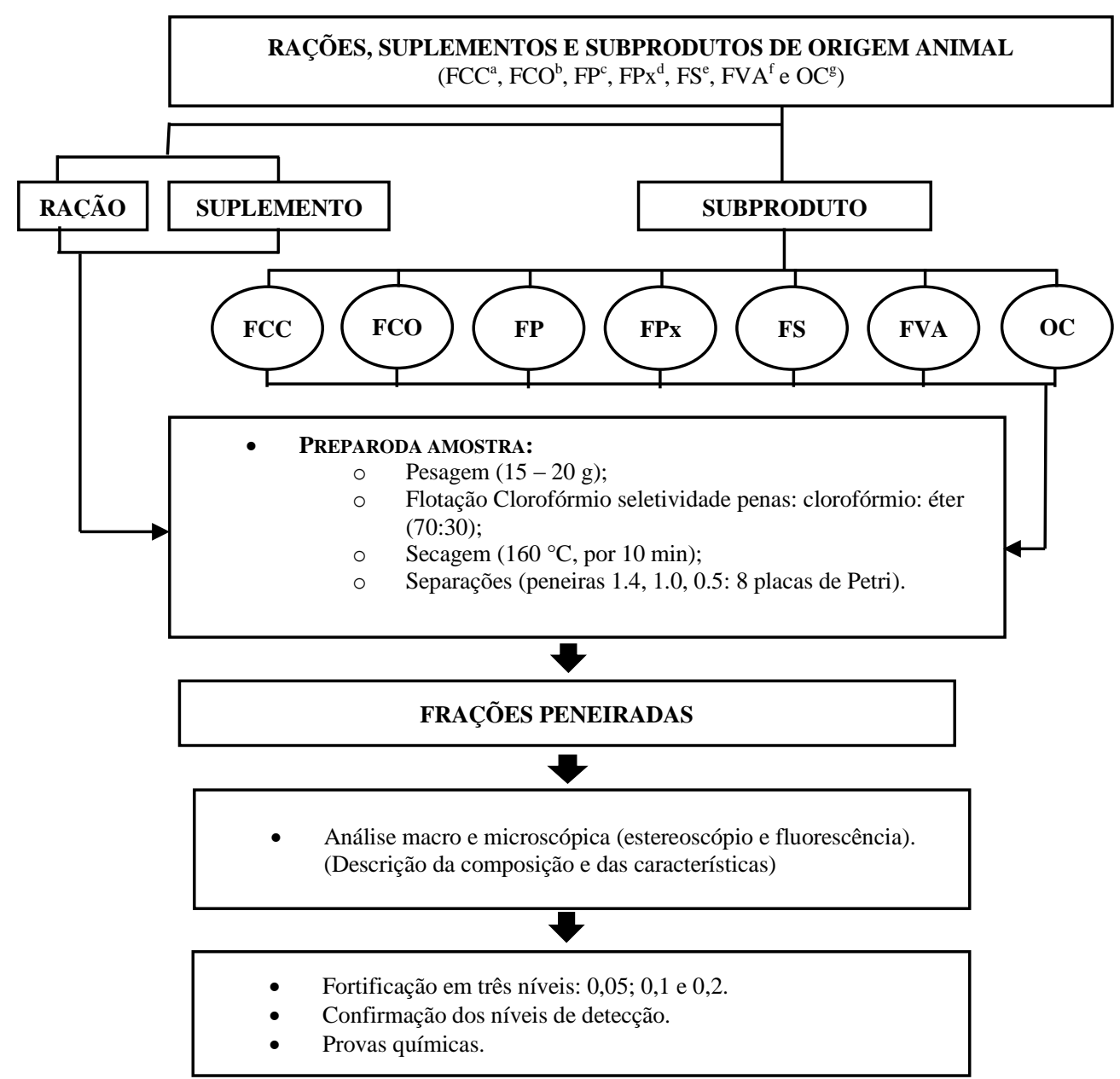

Figura 2: Fluxograma das análises de rações, suplementos e subprodutos de origem animal ( ${ }^{a}$ farinha de cascos e chifres, ${ }^{\mathrm{b}}$ farinha de carne e ossos, ${ }^{\mathrm{c}}$ farinha de penas, ${ }^{\mathrm{d}}$ farinha de peixe, ${ }^{\mathrm{e}}$ farinha de sangue, ${ }^{\mathrm{f}}$ farinha de vísceras de aves e $\mathrm{e}^{\mathrm{g}}$ ossos calcinados).

\section{Resultados e Discussão}

Detalhes das características macro e microscópicas das amostras de rações para ruminantes, suplementos e subprodutos de OA (aves, bovinos, peixes e suínos) obtidos estão descritos nas Tabelas 2 e 3 . Os resultados das provas químicas para confirmação e do $\mathrm{LD}$ do método do MAPA para identificação e avaliação de fraude na avaliação de subprodutos de $\mathrm{AO}$ em rações estão descritos nas Tabelas4 a 6, incluindo critérios de aceitabilidade (Tabela 7).

Características macro e microscópicas de rações $e$ ingredientes de origem animal para alimentação de ruminantes

Das rações, suplementos e subprodutos para ruminantes submetidos a análises macro e microscópicas, foi observado que estavam dentro dos requisitos exigidos pela legislação brasileira quanto às características sensoriais (cor, aspecto, odor); bem como quanto à detecção de subprodutos de OA (Brasil, 2003). (a) Características macroscópicas: os dados obtidos indicam que as amostras apresentavam cor e odor característicos de seus componentes, assim como, seu aspecto. Detalhes das amostras estão descritas na Tabela 2(b) Características microscópicas: já as amostras de rações e seus ingredientes avaliados por microscópio estereoscópico, ambos apresentaram 10\% dederivados de leite (DL) e OC. Os macrominerais mais evidentes foram os (carbonatos, fosfatos e cloreto de sódio) onde 60, 35 e $90 \%$ das amostras os continham, respectivamente. Somente três amostras tiveram a presença de cobre o que equivale a $15 \%$. Referente à presença de diferentes tipos os farelos (arroz, milho, soja, sorgo e trigo) esses foram encontrados em 20,75, 45,30 e 50\% das amostras, respectivamente (Tabela 2). 
Tabela 2. Características macro e microscópicas de componentes de rações para ruminantes obtidospelo Serviço de Fiscalização de Insumos Pecuários

\begin{tabular}{|c|c|c|c|c|c|c|c|c|c|c|c|c|}
\hline \multirow{4}{*}{$\begin{array}{l}\text { Ração } \\
\text { Número }\end{array}$} & \multicolumn{12}{|c|}{ Características e composição das amostras } \\
\hline & \multirow{2}{*}{\multicolumn{2}{|c|}{ Macroscópica }} & \multicolumn{9}{|c|}{ Microscópica } & \multirow{3}{*}{ Subp.OA } \\
\hline & & & \multicolumn{4}{|c|}{ Farelos } & \multicolumn{5}{|c|}{ Suplemento } & \\
\hline & Cor* & Odor & Arroz & Milho & Soja & Sorgo & Trigo & ${ }^{\mathrm{b}} \mathrm{CO}_{3}{ }^{-2}$ & ${ }^{\mathrm{c}} \mathrm{PO}_{4}{ }^{3-}$ & $\mathrm{NaCl}$ & Outros & \\
\hline 1 & Amarela $^{\alpha}$ & Cereal $^{\mathrm{d}}$ & $\mathrm{ND}^{\mathrm{e}}$ & $\mathrm{D}^{\mathrm{f}}$ & $\mathrm{D}$ & ND & $\overline{\mathrm{D}}$ & $\overline{\mathrm{D}}$ & ND & $\overline{\mathrm{D}}$ & ND & ND \\
\hline 2 & Amarela $^{\alpha}$ & Cereal & ND & $\mathrm{D}$ & ND & ND & $\mathrm{D}$ & ND & ND & $\mathrm{D}$ & ND & $\mathrm{OC}^{\mathrm{g}}$ \\
\hline 3 & Amarela $^{\alpha}$ & Cereal & ND & $\mathrm{D}$ & $\mathrm{D}$ & ND & $\mathrm{D}$ & ND & ND & D & ND & $\mathrm{OC}$ \\
\hline 4 & Amarela $^{\alpha}$ & Cereal & ND & $\mathrm{D}$ & ND & ND & ND & $\mathrm{D}$ & ND & D & ND & ND \\
\hline 5 & Marrom $^{\beta}$ & Cereal & ND & D & D & ND & D & D & ND & D & ND & ND \\
\hline 6 & Cinza ${ }^{\text {h, }}$ & $\mathrm{NO}^{\mathrm{i}}$ & ND & ND & ND & ND & ND & $\mathrm{D}$ & D & D & ND & ND \\
\hline 7 & $\operatorname{Cinza}^{\mho}$ & $\mathrm{NO}$ & ND & ND & ND & ND & ND & D & D & D & ND & ND \\
\hline 8 & Amarela $^{\alpha}$ & Cereal & ND & $\mathrm{D}$ & ND & $\mathrm{D}$ & ND & $\mathrm{D}$ & ND & D & ND & ND \\
\hline 9 & Amarela $^{\alpha}$ & Cereal & D & D & ND & $\mathrm{D}$ & D & D & D & D & ND & ND \\
\hline 10 & Marrom $^{\alpha}$ & Cereal & ND & D & ND & $\mathrm{D}$ & D & D & D & D & $\mathrm{Cu}^{\mathrm{j}}$ & ND \\
\hline 11 & Amarela $^{\alpha}$ & Cereal & D & D & D & $\mathrm{D}$ & ND & D & ND & D & $\mathrm{Cu}$ & ND \\
\hline 12 & Marrom $^{\alpha}$ & Leite & D & $\mathrm{D}$ & D & ND & $\mathrm{D}$ & ND & ND & ND & ND & $\mathrm{DL}^{\mathrm{k}}$ \\
\hline 13 & Marrom $^{\alpha}$ & Leite & D & D & ND & ND & D & ND & ND & ND & ND & DL \\
\hline 14 & $\operatorname{Cinza}^{\mho}$ & NO & ND & ND & ND & ND & ND & D & $\mathrm{D}$ & $\mathrm{D}$ & ND & ND \\
\hline 15 & $\operatorname{Cinza}^{\mho}$ & NO & ND & ND & ND & ND & ND & D & D & D & $\mathrm{Cu}$ & ND \\
\hline 16 & $\operatorname{Cinza}^{\mho}$ & NO & ND & ND & ND & ND & ND & D & D & D & ND & ND \\
\hline 17 & Amarelo $^{\alpha}$ & Cereal & ND & $\mathrm{D}$ & D & ND & D & ND & ND & $\mathrm{D}$ & ND & ND \\
\hline 18 & Amarelo $^{\alpha}$ & Cereal & ND & D & D & $\mathrm{D}$ & D & ND & ND & D & ND & ND \\
\hline 19 & Amarelo $^{\alpha}$ & Cereal & ND & D & D & ND & ND & ND & ND & D & ND & ND \\
\hline 20 & Amarelo $^{\alpha}$ & Cereal & ND & D & D & $\mathrm{D}$ & ND & ND & ND & D & ND & ND \\
\hline
\end{tabular}

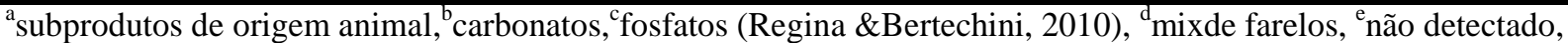
${ }^{\mathrm{f}}$ detectado, ${ }^{\mathrm{g}}$ ossoscalcinados, ${ }^{\mathrm{h}}$ suplementos, ${ }^{\mathrm{i}}$ nãoobservado, ${ }^{\mathrm{j}}$ cobre, ${ }^{\mathrm{k}}$ derivados de leite, tipos de amostras: ${ }^{\alpha}$ granuladas, ${ }^{\beta}$ peletizadase ${ }^{\mho}$ suplementos, *aspecto

Avaliação do método por microscopia para detecção de subprodutos de origem animal proibidos em rações para ruminantes

O método foi avaliado utilizando os subprodutos de OA (FCC, FCO, FP, FPx, FS, FVA e OC) já existentes como padrões (MR) do LM do SLAV/SC do MAPA (Tabela 3). Foi possível identificar suas partículas, constituintes, aspectos organolépticos a níveis baixos $(0,05 \%)$. Esses mesmos foram utilizados para fortificar os próprios subprodutos de $\mathrm{AO}$ para sua aplicação nas provas químicas. Exceção, quando incluída, sem FPx esse LD se elevou a $0,1 \%$ (Tabela 6 ).

Tabela 3. Identificação das características dos subprodutos de origem animal

\begin{tabular}{|c|c|c|}
\hline \multirow{2}{*}{ Amostra } & \multicolumn{2}{|c|}{ Características dos subprodutos } \\
\hline & Macroscópicas & Microscópicas \\
\hline \multicolumn{3}{|c|}{ CASCOS \& CHIFRES } \\
\hline$\overline{\mathrm{FCC}^{\mathrm{a}}(01)}$ & & \\
\hline & $\begin{array}{l}\text { Coloraçãobranca acinzentada. } \\
\text { Fragmentos grossos e tortuosos. }\end{array}$ & $\begin{array}{l}\text { Presença de filamentos de cascos: cinza claro. } \\
\text { Filamentos de chifres brancos e perolados. } \\
\text { Após contato com ácido acético } 50 \% \text { continuaram rígidos. }\end{array}$ \\
\hline
\end{tabular}


Tabela 3. Identificação das características dos subprodutos de origem animal (continuação)

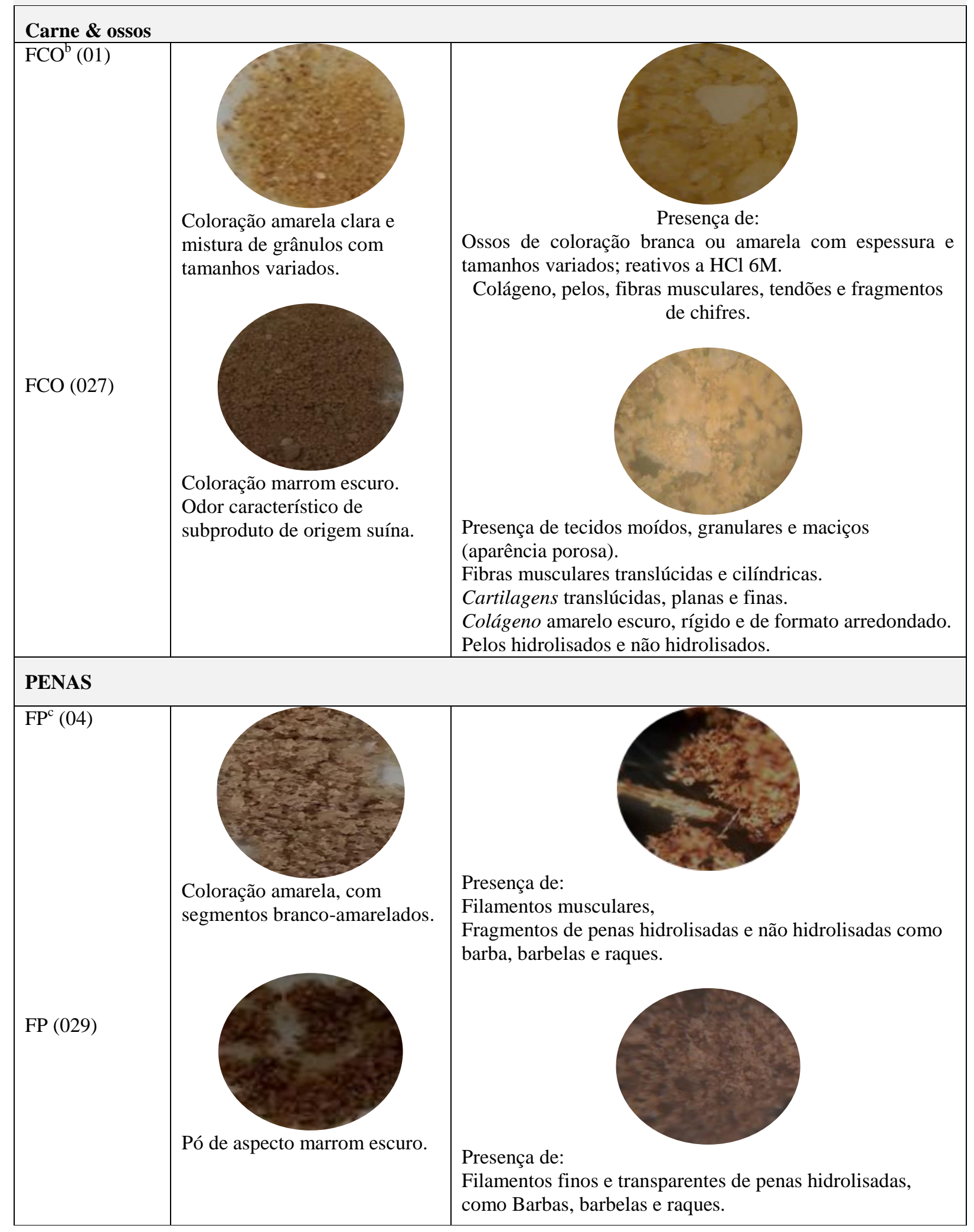


Tabela 3. Identificação das características dos subprodutos de origem animal (continuação)

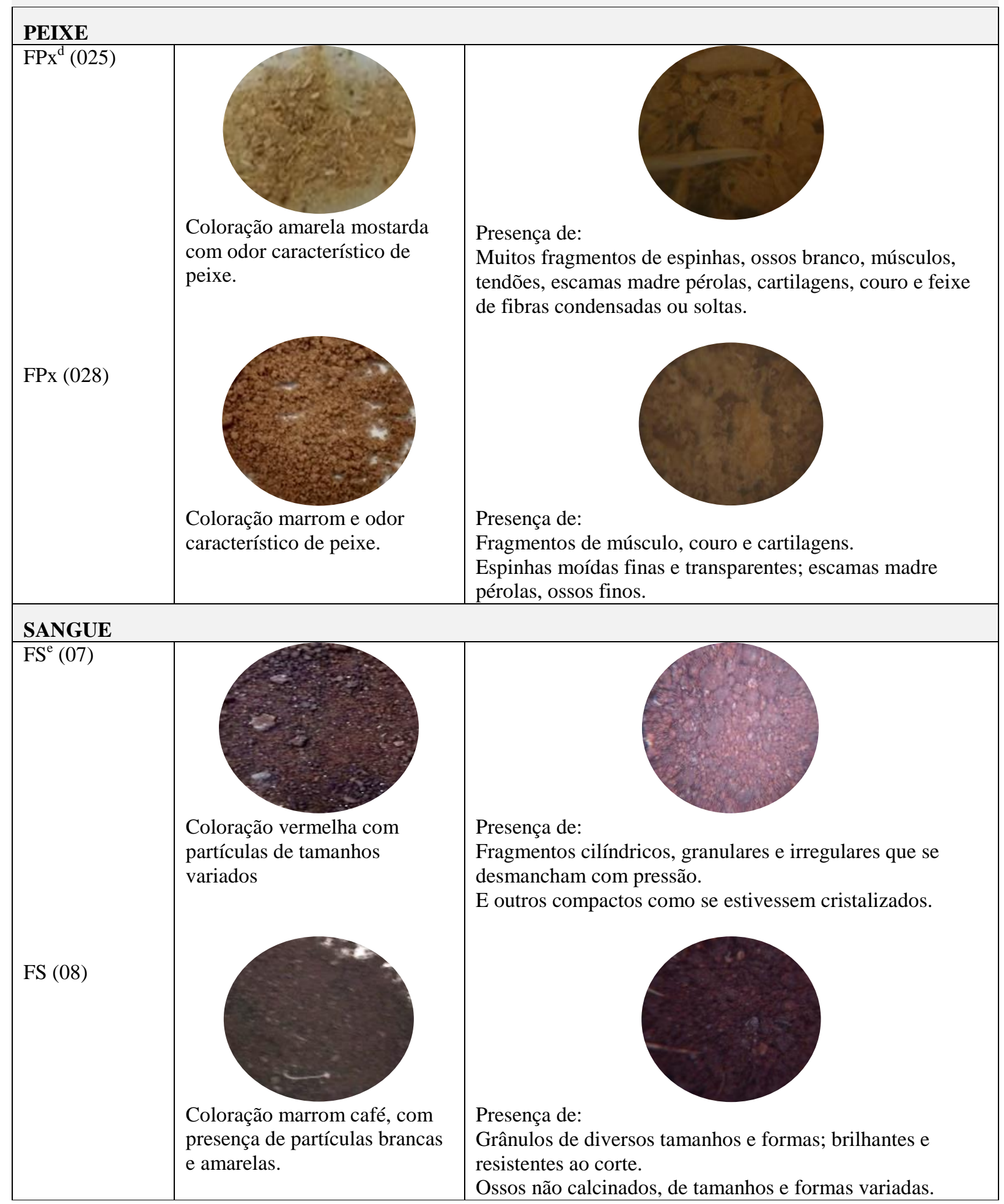


Tabela 3. Identificação das características dos subprodutos de origem animal (continuação)

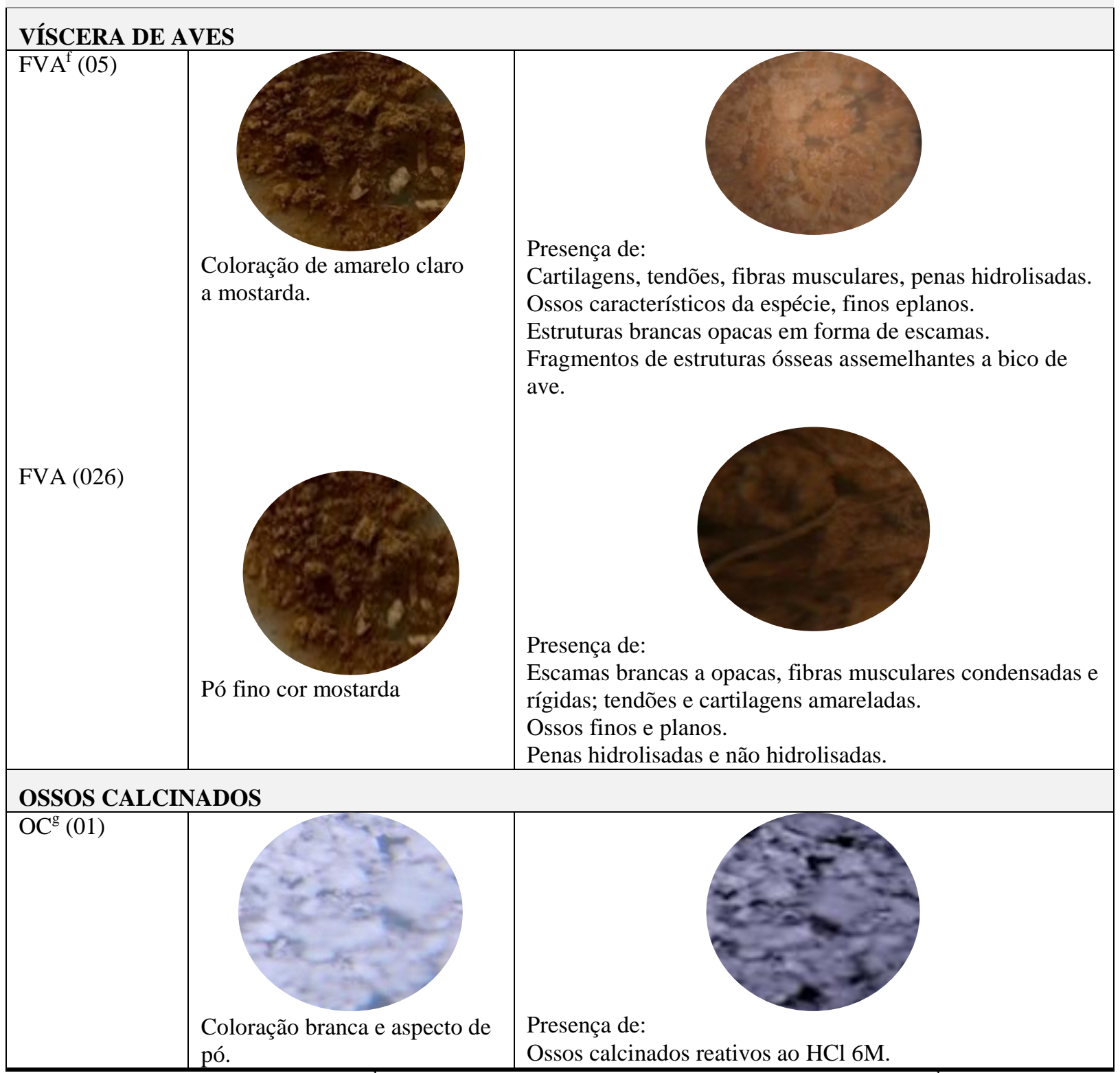

${ }^{a} \mathrm{FCC}$ - Farinha de cascos e chifres, ${ }^{b} \mathrm{FCO}$ - farinha de carne e ossos, ${ }^{c} \mathrm{FP}$ - farinha de penas, ${ }^{\mathrm{d}} \mathrm{FPx}$ - farinha de peixe, ${ }^{\mathrm{e}} \mathrm{FS}$ - farinha de sangue, ${ }^{\mathrm{f}} \mathrm{FVA}$ - farinha de vísceras de aves e ${ }^{\mathrm{g}} \mathrm{OC}$ - ossos calcinados

Características das farinhas: as farinhas de subprodutos de OA são submetidas a altas temperaturas, que acarretam a formação de compostos de Maillard e pontes de dissulfeto, considerados fatores antinutricionais (Berchielli et al., 2011). No entanto são fontes de proteínas importantes para a complementação nutricional de animais de criação e retiradas muitas vezes de resíduos de abatedouros, colaboram para a conservação ambiental (Bellver, 2010). Isso explica a presença de muitas fibras musculares, tendões, ossos, escamas, caudas e nadadeiras de peixes; fragmentos de bicos de aves, penas e uma infinidade de outros subprodutos nas rações. A pesquisa histológica e morfológica das partículas através do microscópio estereoscópico (aumento de 10X) tem como princípio a identificação desses subprodutos utilizando MR desses tecidos para comparação, seguido de aplicação de provas químicas para a confirmação (Momcilovic \& Rasooly, 2000).

Segundo Butolo (2002), as características visuais da FCO são de partículas marrom (claro e escuro), granular e ossos com variadas cores e tamanhos, além de aparência gordurosa e efervescência característica de ONC (Figura 3.a). Ao estereoscópio as partículas de pó estão aderidas a gordura. Os ossos apresentam várias tonalidades (Campestrini, 2005). É obtida através 
de ossos e tecidos de resíduos de abatedouros (moídos e prensados)com aplicação deBoas Práticas de Fabricação. Porém não devem possuir sangue, cascos, chifre, pelos e/ouconteúdo estomacal (Bellever, 2010). Não foram encontradas contaminações por sangue nas amostras analisadas, porém na amostra FCO foram encontrados pelos e chifre, uma contaminação facilmente detectada pela microscopia, porém que não é permitida (Raamsdonk et al., 2011; Brasil,2003).

A FP é composta por estruturas de canhões de penas em forma de tubos plásticos firmes, ocos e de coloração amarelada devido à queratina. Podem estar presentes partículas de bico, unhas, fragmentos de ossos grandes, escamas do tarso e pés. É permitida a presença de sangue,em torno de 5\% (Bellever, 2010) ou em quantidade que não comprometa a qualidade do produto (Butolo, 2002; Fireman, 2010).

Os FCC constituem contaminação da FCO, pois não devem ser acrescentados a rações por sua deficiência nutricional e denunciam a deficiência da aplicação deBoas Práticas de Fabricação.As FPx são constituídas de partes depeixe como cabeça, vísceras e barbatanas; sem a presença de fragmentos de crustáceos (Bellever, 2010). As definições das características da FPx são de suma importância visto que a Diretiva 956 da União Europeia (CE, 2008) libera a utilização de FPx como constituinte na alimentação de ruminantes jovens deste que não esteja contaminada com outros subprodutos de OA (UE, 2008). Todavia, no Brasil FPx ainda é proibida para este uso.A FS não deve ser obtida a partir da secagem do sangue em temperaturas moderadas (devido à produção de complexos com a lisina que não são digeridos, pelos animais) e não pode ser produzida com pelos e conteúdo estomacal (Bellever, 2010). Na descrição de Butolo (2002) a FS apresenta esferas secas e quebradiças de coloração vermelha a preta; contudo, pode ser contaminada com fragmentos de ossos, pelos e fibras vegetais do rúmen pela falta de higiene dos equipamentos.A FVA não deve apresentar cascas e ovos, mas é composta por restos do processamento de víscera de aves, pés, cabeças e restos de incubatório. Bellever (2010), por sua vez, considera a presença de resíduos de ovos e restos incubatório uma contaminação por adulteração. Os OC são subprodutos permitidos na alimentação de ruminantes, desde que não apresentem partículas de ONC (Brasil, 2004). É um pó de aspecto branco leitoso e de partículas bem finas(Butolo,2002).

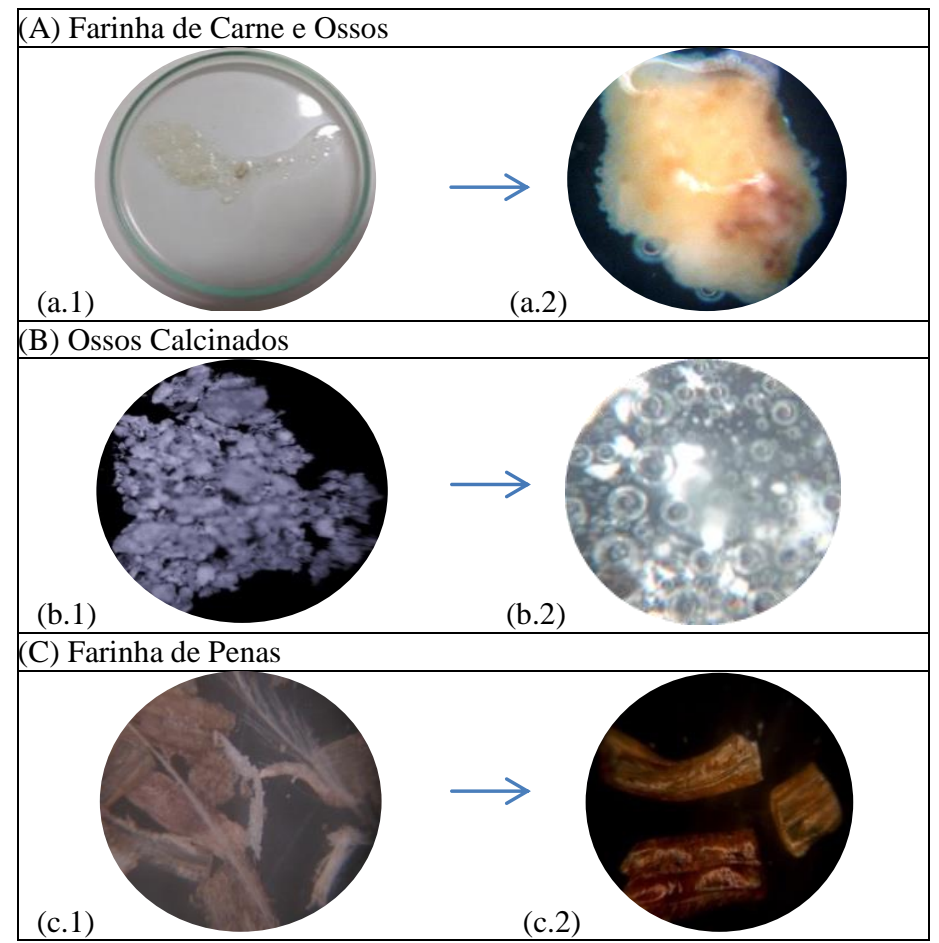

Figura 3. Amostra de farinha de (A) carne e ossos preparada para análise: (a.1) e (a.2)análise da efervescência de ossos não calcinados em ácido clorídrico(com efervescência lenta) e formação de estrutura gelatinosa, (B) ossos calcinados: análise da efervescência de ossos calcinados em ácido clorídrico (com efervescência rápida) e (C) penas: (c.1) presença de penas e (c.2) presença de raques de penas escurecidas pelo reagente 
Provas químicas na detecção de subprodutos de AO em ração para ruminantes

Segundo o Inmetro, o LD é a menor quantidade do analitopresente na amostra que a distingue do zero (Controle: sem analito) (Brasil, 2010). Já o MAPA, o considera como limite mínimo detectável do analito (Brasil, 2011). Portanto, os resultados foram expressos em ND (não detectado) quando não foi possível a detecção de subprodutos de OA e D (detectado), quando foi possível a percepção das partículas de subprodutos de OA, citando os LD obtidos em procedimentos de validação para os analitos pesquisados (Brasil, 2003; Sancheset al., 2006). Os testes de deteç̧ão foram desenvolvidos primeiramente selecionando o LD para cada analito pesquisado (Tabela 4), seguido da porcentagem encontrada (objetivo de confirmar o LD) para FCC, ONC, FP e FS (Tabelas 5 e 6, respectivamente) (Rossetto, 2015).

Tabela 4. Níveis de contaminação e resultados obtidos através de provas químicas de subprodutos de AO em ração para ruminantes

\begin{tabular}{|c|c|c|c|c|c|c|}
\hline \multirow{3}{*}{ Identificação } & \multirow{3}{*}{ Fortificação, \% } & \multicolumn{4}{|c|}{ Peso, $\mathrm{g}$} & \multirow{3}{*}{ Resultados } \\
\hline & & \multicolumn{2}{|c|}{ Analito } & \multicolumn{2}{|c|}{ Fortificação } & \\
\hline & & $\mathrm{OC}_{1 \mathrm{x}, 2 \mathrm{x}}^{\mathrm{a}}$ & $\mathrm{FPx}_{3 \mathrm{x}}^{\mathrm{b}} / \mathrm{FCO}^{\mathrm{c}}{ }_{4 \mathrm{x}}$ & $\mathrm{ONC}_{1 \mathrm{y}}^{\mathrm{d}} / \mathrm{FS}_{2 \mathrm{y}}^{\mathrm{e}}$ & $\mathrm{FP}_{3 \mathrm{y}}^{\mathrm{f}} / \mathrm{FCC}_{4 \mathrm{y}}^{\mathrm{g}}$ & \\
\hline Controle $^{\mathrm{h}}$ & $\mathrm{NA}^{\mathrm{i}}$ & 2,00 & 20,00 & NA & $\overline{\mathrm{NA}}$ & $\mathrm{ND}^{\mathrm{j}}$ \\
\hline 1 & 0,05 & 1,9990 & 19,9900 & 0,0010 & 0,0100 & $D^{k}$ \\
\hline 2 & 0,1 & 1,9980 & 19,9800 & 0,0020 & 0,0200 & $\mathrm{D}$ \\
\hline 3 & 0,2 & 1,9960 & 19,9600 & 0,0040 & 0,0400 & $\mathrm{D}$ \\
\hline
\end{tabular}

${ }^{\mathrm{a}}$ ossos calcinados, ${ }^{\mathrm{b}}$ farinha de peixe, ${ }^{\mathrm{c}}$ farinha de carne e ossos, ${ }^{\mathrm{d}}$ ossos não calcinados, ${ }^{\mathrm{e}}$ farinha de sangue, ${ }^{\mathrm{f}}$ farinha de penas, ${ }^{\mathrm{g}}$ farinha de cascos e chifres, ${ }^{\mathrm{h}}$ semfortificação, ${ }^{\mathrm{i}}$ nãoaplicável, ${ }^{\mathrm{j}}$ não detectado, ${ }^{\mathrm{k}}$ detectado, ${ }_{1 \mathrm{x}}$ analito $\mathrm{x}_{1 \mathrm{y}}$ fortificação, respectivamente.

Tabela 5. Confirmação do limite de detecção para subprodutos de origem animalpor provas químicas

\begin{tabular}{|c|c|c|c|c|c|c|}
\hline \multirow{3}{*}{ Identificação } & \multirow{3}{*}{ Fortificação, \% } & \multicolumn{4}{|c|}{ Peso, $g$} & \multirow{3}{*}{ Resultados } \\
\hline & & \multicolumn{2}{|c|}{ Analito } & \multicolumn{2}{|c|}{ Fortificação } & \\
\hline & & $\mathrm{OC}^{\mathrm{c}}{ }_{1 \mathrm{x}} / \mathrm{ONC}_{2 \mathrm{x}}^{\mathrm{d}}$ & $\mathrm{FPx}_{3 \mathrm{x}}^{\mathrm{e}} / \mathrm{FCO}_{4 \mathrm{x}}^{\mathrm{f}}$ & $\mathrm{ONC}_{1 \mathrm{y}} / \mathrm{FS}_{2 \mathrm{y}}^{\mathrm{g}}$ & $\mathrm{FP}_{3 \mathrm{y}}^{\mathrm{h}} / \mathrm{FCC}_{4 \mathrm{y}}^{\mathrm{i}}$ & \\
\hline Controle $^{a}$ & $\mathrm{NA}^{\mathrm{b}}$ & 2,00 & 20,00 & $\overline{\mathrm{NA}}$ & $\mathrm{NA}$ & $\mathrm{ND}^{\mathrm{j}}$ \\
\hline 1 & 0,05 & 1,9990 & 19,9900 & 0,0010 & 0,0010 & $\mathrm{D}^{\mathrm{k}}$ \\
\hline 2 & 0,05 & 1,9990 & 19,9900 & 0,0010 & 0,0010 & $\mathrm{D}$ \\
\hline 3 & 0,05 & 1,9990 & 19,9900 & 0,0010 & 0,0010 & $\mathrm{D}$ \\
\hline 4 & 0,05 & 1,9990 & 19,9900 & 0,0010 & 0,0010 & $\mathrm{D}$ \\
\hline 5 & 0,05 & 1,9990 & 19,9900 & 0,0010 & 0,0010 & $\mathrm{D}$ \\
\hline 6 & 0,05 & 1,9990 & 19,9900 & 0,0010 & 0,0010 & $\mathrm{D}$ \\
\hline
\end{tabular}

a semfortificação, ${ }^{b}$ ãoaplicável, ${ }^{c}$ ossos calcinados, ${ }^{\mathrm{d}}$ ossos não calcinados, ${ }^{\mathrm{e}}$ farinha de peixe, ${ }^{\mathrm{f}}$ farinha de carne e ossos, ${ }^{\mathrm{g}}$ farinha de sangue, ${ }^{\mathrm{h}}$ farinha de penas, ${ }^{\mathrm{i}}$ farinha de cascos e chifres, ${ }^{\mathrm{j}}$ nãodetectado, ${ }^{\mathrm{k}}$ detectadoe, ${ }_{1 \mathrm{x}}$ analito $\mathrm{x}$ ${ }_{1 y}$ fortificação, respectivamente

A detecção de sangue, em partículas não sanguíneas foi possível devido à coloração das partículas de hemácias, as quais são muito características (variando de vermelho ao bordeaux escuro) e sua opacidade as difere das partículas de sais (Sanches et al., 2006). Como resultado, deve ser registrada a coloração vermelha (quando a partícula é analisada em microscópio de fluorescência). O LD de sangue foi de $0,05 \%$ confirmando os achados reportados por Sanches et al. (2006) (Tabela 7).

A análise microscópica da presença de fragmentos de ONC se dá pela comparação do tempo de efervescência (Figura 3.a)a qual é mais lenta e com a formação de uma estrutura gelatinosa - o que não acontece com as partículas de OC (Figura 3.B), onde a efervescência é rápida e as partículas desaparecem (Khajarern \& Khajarern, 1999). O LD de ONC em OC permaneceu em $0,05 \%$ conforme descrito por Sanches et al. (2006), e foi confirmado pela prova química utilizado como reagente, o ácido clorídrico (Campestrini, 2005; Khajarern \& Khajarern, 1999).

$\mathrm{Na}$ pesquisa de cascos e chifres as placas de Petri contendo frações com granulometria de 1,00 e $0,05 \mathrm{~mm}$ (onde estão localizados os minerais) são as mais prováveis de encontrar tais estruturas por conterem as partículas mais pesadas. Quando da suspeita de tais achados, são retiradas 2ou 3 
partículas suspeitas e acrescentado ácido acético 1:1 (5mL),seguido de repouso por $60 \mathrm{~min}$. Os cascos e chifres continuam duros, firmes e não quebradiços. Já as outras partículas contendo proteínas, ficam macias e fáceis de partir (Campestrini, 2005; Khajarern \& Khajarern, 1999).

Tabela 6. Confirmação do limite de detecção de farinha de penasem farinha de peixe

\begin{tabular}{|c|c|c|c|c|c|c|c|c|}
\hline \multirow{3}{*}{ Identificação } & \multirow{2}{*}{\multicolumn{2}{|c|}{$\begin{array}{c}\text { Níveis de } \\
\text { Fortificação, \% }\end{array}$}} & \multicolumn{4}{|c|}{ Peso, $\mathrm{g}$} & \multirow{2}{*}{\multicolumn{2}{|c|}{$\mathrm{LD}^{\mathrm{c}}, \%$}} \\
\hline & & & \multicolumn{2}{|c|}{ Matriz $(\mathrm{FPx})^{\mathrm{a}}$} & \multicolumn{2}{|c|}{ Fortificação(FP) $^{b}$} & & \\
\hline & (1) & (2) & Análise(1) & Análise(2) & (1) & (2) & 0,05 & 0,1 \\
\hline Controle $^{\mathrm{d}}$ & $\mathrm{NA}^{\mathrm{e}}$ & NA & 20,0000 & 20,0000 & $\overline{\mathrm{NA}}$ & NA & $\mathrm{ND}^{\mathrm{f}}$ & $\overline{\mathrm{ND}}$ \\
\hline 1 & 0,05 & 0,1 & 19,9900 & 19,9800 & 0,0100 & 0,0200 & $\mathrm{D}^{\mathrm{g}}$ & $\mathrm{D}$ \\
\hline 2 & 0,05 & 0,1 & 19,9900 & 19,9800 & 0,0100 & 0,0200 & ND & $\mathrm{D}$ \\
\hline 3 & 0,05 & 0,1 & 19,9900 & 19,9800 & 0,0100 & 0,0200 & $\mathrm{D}$ & $\mathrm{D}$ \\
\hline 4 & 0,05 & 0,1 & 19,9900 & 19,9800 & 0,0100 & 0,0200 & $\mathrm{D}$ & $\mathrm{D}$ \\
\hline 5 & 0,05 & 0,1 & 19,9900 & 19,9800 & 0,0100 & 0,0200 & ND & $\mathrm{D}$ \\
\hline 6 & 0,05 & 0,1 & 19,9900 & 19,9800 & 0,0100 & 0,0200 & $\mathrm{D}$ & $\mathrm{D}$ \\
\hline
\end{tabular}

${ }^{a}$ farinha de peixe, ${ }^{b}$ farinha de penas, ${ }^{c}$ limite de detecção, ${ }^{d}$ sem fortificação, ${ }^{e}$ não aplicável, ${ }^{f}$ não detectado $\mathrm{e}^{\mathrm{g}}$ detectado

A FP foi possível de ser detectada até $0,05 \%$ de fortificação (Tabela 6), análise (1), obtendo recuperação $(71 \%)$ baixa o que não comprova o método: ideal próximo a 100\% (Brasil, 2010). Foi realizada repetição [Tabela 6 , análise (2)] utilizando fortificação de $0,1 \%$ e foi obtido $100 \%$ de detecção nas amostras de FP em FPx, contrariando Sanches et al. (2006) que estipula um limite de $0,05 \%$ para este teste. As partículas suspeitasforam confirmadas com o reagente de cistina (acetato de chumbo e hidróxido de sódio $10 \%$ ) com o escurecimento das partículas (Figura 3.c.2) em ambas as fortificações (UE, 2009).

\section{Discussão geral}

Embora, tenha sido observado que os LD para subprodutos de OA, no presente estudo, variam entre 0,5 e 0,1\% (Eckhardt et al., 2013 e Sancheset al., 2006) reportam variação de 0,05 a $0,80 \%$ para FCA, OC, FP, FPx e de 0,10 a $0,80 \%$ para FVA. Contudo Raamsdonk et al., (2011) encontraram LD de $0,02 \%$ de subprodutos de OA como a FCO, FP, FPx, porém citam como desvantagem a dificuldade de identificar as espécies de animais utilizados.AUnião Europeia estipula que os subprodutos de OA identificados pelo método de microscopia (estereoscópico) deva ter especificidade menor que $0,1 \%$ (UE, 2009),estando então, as análises do LD do presente trabalho dentro dos parâmetros estipulados pela legislação internacional (europeia) (Tabela 7).

Tabela 7. Critério de aceitabilidade e limites de detecção do método aplicado para subprodutos de origem animal em amostras de rações para ruminantes

\begin{tabular}{llll}
\hline \multirow{2}{*}{ Subprodutos, farinhas } & $\mathrm{LD}^{\mathrm{a}}$ & & \\
\cline { 2 - 3 } & Critério de aceitabilidade, \% & Valores obtidos, \% & Conclusão (UE, 2009) $^{\mathrm{b}}$ \\
\hline Cascos e chifres & 0,1 & 0,05 & Conforme \\
Penas & 0,1 & 0,10 & Conforme \\
Sangue & 0,1 & 0,05 & Conforme \\
Ossos não calcinados & 0,1 & 0,05 & Conforme \\
\hline
\end{tabular}

${ }^{a}$ limite de detecção (Sanches et al., 2006), ${ }^{b}$ conforme legislação internacional - Comunidade Europeia (UE, 2009)

\section{Conclusão}

As rações para ruminantes avaliadas macro e microscopicamente apresentaram características que são consideradas adequadas (dentro dos padrões estabelecidos pelo MAPA), não apenas no aspecto, como também na ausência de subprodutos OA proibidos na alimentação de ruminantes. A avaliação do método com definição do LD juntamente com provas químicas, confere maior confiabilidade aos resultados e também contribui para o desenvolvimento da acuidade visual do analista.

Através deste estudo foi possível concluir que o método microscópico para detecção de subprodutos de OA é eficiente e apurado para os principais subprodutos utilizados em alimentação 
animal, o que torna a análise microscópica de rações uma ferramenta útil, barata e de fácil execução na mitigação de risco à EEB.

\section{Agradecimentos}

Agradecemos ao Laboratório de Microscopia do Ministério da agricultura, Pecúaria e Abastecimento (MAPA) por ceder às amostras e padrões de referência necessários para a execução do trabalho.

\section{Referências Bibliográficas}

AAFM. 1992. American Association of Feed Microscopists (1992). Manual of microscopic analysis of feedstuffs (3 ${ }^{\text {th }}$ ed.), 113-145. AAFM. USA.

Bellever, C. Farinhas e gorduras de origem animal. 2010 In: Regina, R. (Coord.). Nutrição animal, principais ingredientes $e$ manejo de aves e suínos. São Paulo: Fundação Cargill, 126-153.

Berchielli, T. T., Pires, A. V. \& Simone G. O. 2011. Nutrição para Ruminantes. ( $2^{\mathrm{a}}$ ed.), Jaboticabal: FUNEP, 616.

Bittar, C. M. 2006. Minerais e aditivos para bovinos. Anais do $8^{\circ}$ simpósio sobre nutrição de bovinos. Piracicaba: FEALQ, 77-129.

Brasil. 2003. Ministério da Agricultura, Pecuária e Abastecimento. Instrução Normativa n. 69, de 23 de setembro de 2003. Aprova a padronização da metodologia para deteç̧ão de subprodutos de origem animal em misturas de ingredientes para alimentação de ruminantes por microscopia. Brasília: Diário Oficial da União.

Brasil. 2004. Ministério da Agricultura, Pecuária e Abastecimento. Instrução Normativa $\mathrm{n}^{\circ} 8$, de 25 de março de 2004. Pró́be em todo o território nacional a produção, a comercialização e a utilização de produtos destinados à alimentação de ruminantes que contenham em sua composição proteínas e gorduras de origem animal. Brasília: MAPA.

Brasil. 2008. Ministério da Agricultura, Pecuária e Abastecimento. Encefalopatia Espongiforme Bovina - EEB: doença da vaca louca. Cartilha. Secretaria de Defesa Agropecuária. Brasília: MAPA/SDA, 24.

Brasil. 2010. Instituto Nacional de Metrologia, Normatização e Qualidade Industrial. Orientação sobre validação de métodos analíticos - DOC-CGCRE-008. Revisão 3. Rio de Janeiro: INMETRO.20.

Brasil. 2011. Ministério da Agricultura, Pecuária e Abastecimento. Guia de validação e controle de qualidade analítica: fármacos em produtos para alimentação e medicamentos veterinários. Brasília: MAPA/ACS.

Brasil. 2015. Ministério da Agricultura, Pecuária e Abastecimento. Bovinos e Bubalinos.Brasília: MAPA.

ButoloJ.E. Qualidade de ingredientes na alimentação animal. 2002. Campinas: J.E., 430 .

Campestrini E. Farinha de carne e ossos. 2005. Revista Nutritime, v.2, n.4, jul./ago. art. $\mathrm{n}^{\circ}$ 24.221-234.

EU. 2008. - União Europeia. Diretiva n. ${ }^{\circ}$ 956/2008/CE altera o Anexo IVda Diretiva n. ${ }^{\circ}$ 999/2001/CE, que estabelece regras para a prevenção, controle e erradicação de determinadas Espongilites Espongiformes Transmissíveis. G260, 8-11. Bruxelas: Jornal Oficial da União Europeia.

UE. 2009. União Europeia. Diretiva $\mathrm{n}^{\circ}$ 152/2009/CE estabelece os métodos de amostragem e de análise para o controlo oficial dos alimentos para animais. L54, 103107. Bruxelas: Jornal Oficial das Comunidades Europeias.

Eckhardtl D. C., Gräff A., Salvatori R .U. \& Strohschoen, A. A. 2013. Pesquisa de constituintes de origem animal em rações de aves utilizando microscopia óptica. Revista Eletrônica Nutritime, Maio/Jun, art. 198, v.10, n. 03, $2390-2407$.

Fireman, A. K. 2010. A escolha de aditivos para alimentação animal na indústria de aves e suínos. In: Regina, R, (Coord.). Nutrição animal, principais ingredientes e manejo de aves e suínos. São Paulo: Fundação Cargill, 205-247.

Gabbi A. M., Cypriano L. \& Piccinin I. 2011. Aspectos microbiológicos e físico-químicos de três rações comerciais sob diferentes condições de armazenamento. Salvador: Revista Brasileira de Saúde e Produção Animal,jul/set, v.12, n.3, 784-793.

Momcilovic, D. \& Rasooly, D. 2000. Detection and analysis of animal materials in food and 
feed.Journal of Food Protection, vol. 6, n. 11, 1602-109.

Morita, T. \& Assumpção, R. M. V. 2007. Manual de soluções, reagentes e solventes: padronização, preparação, purificação com indicadores de segurança e de descarte de produtos químicos. São Paulo: Blucher, 675.

OIE. 2014. - World Organisation for Animal Health. Member Countries Oficial Bovine Spongiform en Encephalopathy risk status map. France: OIE.

Raamsdonk L., PinottI. L.,Veys P., Bremer M., HekmanW., Kemmers, A., Campagnoli, A. C., Paltanin C., Crespo C. B., Vliege, J., Pinckaers, V. \& Jørgensen J. S. 2011. New developments in classical microscopy. Biotechnol.Agron. Soc. Environ. 15(S1), 1524.

Regina R. \& Bertechini A. G. Minerais. In: Regina, R. (coord.). 2010. Nutrição animal, principais ingredientes e manejo de aves $e$ suínos. São Paulo: Fundação Cargill, 172-205.

Rossetto J. F. 2015. Microscopia de rações para ruminantes e subprodutos de origem animal: ferramenta de mitigação de risco à encefalopatia espongiforme bovina. TCC, Farmácia-Bioquímica Habilitação em Tecnologia de Alimentos, UFSC, SC.

Sanches R. L., Filho, J. F. A., Souza, V. C. \& Junqueira, R. G. 2006. In-house validation of method for detection of animal meals in ruminant feeds by microscopy. Food Control $17,85-92$.

Recebido em Agosto 25, 2015.

Aceito em Outubro 7, 2015.

License information: This is an open-access article distributed under the terms of the Creative Commons Attribution License, which permits unrestricted use, distribution, and reproduction in any medium, provided the original work is properly cited. 